\section{MILITANTES ENTRE EL SER Y EL DEBER SER. COMPROMISO, GÉNERO Y FAMILIAS EN LA JUVENTUD REVOLUCIONARIA DE LOS AÑOS SETENTA EN ESPAÑA Y ARGENTINA}

\author{
Bárbara Ortuño Martínez \\ Universidad de Alicante \\ ORCID iD: https://orcid.org/0000-0003-3864-9086 \\ barbara.ortuno@ua.es \\ Mónica Moreno Seco \\ Universidad de Alicante \\ ORCID iD: https://orcid.org/0000-0002-3219-8790 \\ monica.moreno@ua.es
}

Cómo citar este artículo/Citation: Ortuño Martínez, B. y Moreno Seco, M. (2020). Militantes entre el ser y el deber ser. Compromiso, género y familias en la juventud revolucionaria de los años setenta en España y Argentina. Arbor, 196 (796): a553. https://doi.org/10.3989/arbor.2020.796n2006

Recibido: 26 mayo 2018. Aceptado: 23 octubre 2019.

RESUMEN: Desde una perspectiva transnacional y comparada, que incorpora la experiencia del exilio, este trabajo analiza las tensiones identitarias que afectaron a la juventud militante de la izquierda revolucionaria española y argentina durante los años setenta. A través de las relaciones familiares y de género, estudia las formas públicas y privadas del compromiso y la transgresión. Aborda cómo la politización de lo privado marcó a hombres y mujeres dentro de un proceso global contestatario, heredero del 68, para destacar las contradicciones que afloraron entre la teoría y la práctica, el deseo y la realidad, que llevaron a los jóvenes militantes a asumir un régimen emocional en constante debate entre el ser y el deber ser.

PALABRAS CLAVE: Transgresión; militancia; género; años setenta; izquierda revolucionaria; España-Argentina.

\section{MILITANTS: WHO THEY WERE AND WHO THEY WERE SUPPOSED TO BE. COMMITMENT, GENDER AND FAMILIES IN REVOLUTIONARY YOUTH OF THE SEVENTIES IN SPAIN AND ARGENTINA}

Copyright: (C) 2020 CSIC. Este es un artículo de acceso abierto distribuido bajo los términos de la licencia de uso y distribución Creative Commons Reconocimiento 4.0 Internacional (CC BY 4.0).

ABSTRACT: From a transnational and comparative perspective, which includes the experience of exile, this paper analyses the identity crises experienced by the militant youth of the Spanish and Argentinian revolutionary left during the seventies. By studying family and gender relations, it focuses on both public and private commitment and transgression. It considers how the politicization of the private sphere influenced men and women within a global protest process, the heir to ' 68 , in order to emphasize the contradictions between theory and practice, and desire and reality, which led young militants to accept an emotional regime in which there was a constant debate between who they were and who they were supposed to be.

KEYWORDS: Transgression; commitment; gender; seventies; new left; Spain-Argentina. 


\section{INTRODUCCIÓN}

El estudio de los años 68 conjuga el interés por los acontecimientos con el análisis de las culturas políticas y las formas de vida (Frank, 2000, pp. 13-15). En una era de contestación, el compromiso era político y también personal, al tiempo que la transgresión tuvo dimensiones públicas y privadas, plasmadas en ideas, acciones y comportamientos cotidianos. Pero las experiencias, proyectos y emociones de estos años de profundos cambios no siempre afectaron por igual a mujeres y hombres (Evans, 2009). En este trabajo focalizamos la atención en la juventud militante de la izquierda revolucionaria en España y en Argentina, dos países sometidos a dictaduras y donde surgieron dinámicos partidos en que ingresaron numerosas jóvenes, que compartieron activismo con sus compañeros varones. Nos interesa también la vía del exilio argentino porque a pesar de los avances experimentados en este campo de estudios durante los últimos años (Coraza de los Santos y Gatica, 2018; Lastra, 2018), el caso español todavía no se ha abordado desde una perspectiva de género que tenga en cuenta la militancia. Asimismo, consideramos que la vivencia de la expatriación, además de reforzar ese espacio transnacional conformado por la península ibérica y la república austral, sumó nuevas tensiones a una subjetividad militante que transitó por múltiples derroteros.

Nuestros objetivos, por tanto, se concretan, en primer lugar, en analizar las contradicciones y reconfiguraciones identitarias que surgieron cuando el compromiso y la transgresión cuestionaron las relaciones familiares y de género de la época. Como señala Mamzer (2006), las transgresiones al orden de género provocan modificaciones en las identidades subjetivas y colectivas. En segundo término, proponemos calibrar el impacto diferenciado en mujeres y hombres de estas experiencias que difuminaron las fronteras entre lo público y lo privado. Por último, desde una perspectiva transnacional y comparada, en la línea de otros estudios centrados en Europa o Estados Unidos (Horn, 2007; Klimke y Scharloth, 2008), pretendemos señalar los elementos comunes y las especificidades presentes en el caso español, en la experiencia argentina y en la comunidad exiliada, en el contexto de la cultura juvenil global de la época. Como veremos a continuación, el deseo de que la revolución política se convirtiera en revolución de los cuerpos no estuvo exento de paradojas y se convirtió en uno de los principales legados del 68 (Clifford, Gildea y Warring, 2013).

Los años setenta fueron una etapa histórica de profundas transformaciones en el espacio social y políti- co, pero también en la vida privada. En Estados Unidos, en Europa y en los países del Tercer Mundo existió la convicción de que "otro mundo era posible". La juventud pasó a ser un actor autónomo en la escena política y social. Manifestó su malestar con el sistema establecido y lo expresó de diferentes modos, desde actitudes contestatarias más privadas hasta propuestas de acción revolucionaria. En una época de protesta en todo el planeta, irrumpió una cultura rebelde y transgresora de carácter transnacional, que permitía sentir como propio lo que sucedía en Saigón, París, Praga o Chicago, pues "el mundo había encogido" (Eley, 2003, p. 339). Según la expresión de Hobsbawm (1998, p. 438), "la revolución se vivía como una luna de miel colectiva".

Sin embargo, cada vez contamos con más indicios sobre la coexistencia de diversas subculturas juveniles (Carassai, 2013; Cattaruzza, 2008), pues hubo diferentes formas de ser y sentirse joven, así como distintas maneras de ser y sentirse hombre o mujer. Como ha señalado Andrea Andújar,

Guerrilleras, feministas, sindicalistas, rockeras; microscópicas minifaldas o largas túnicas multicolores, armas en la cartera o micrófono en mano [...] daban cuenta de mujeres con horizontes diversos y experiencias que, no sin contradicciones, iban construyendo otras formas de ser y de relacionarse (Andújar, 2009, p. 150).

Se plantearon diferentes respuestas a la insatisfacción con los valores tradicionales y la "vieja política", entre las que pueden señalarse el hedonismo, diferentes movimientos sociales, la nueva izquierda e incluso el recurso a la violencia. La militancia en formaciones políticas de la extrema izquierda se presentó como una opción atractiva para parte de esta juventud rebelde, pues se ajustaba a la urgencia por el cambio y la entrega al activismo, y se distanciaba de partidos o sectores políticos ortodoxos y controlados por una generación adulta. A la clásica crítica marxista de que el izquierdismo era la enfermedad infantil del comunismo, esta juventud militante respondía que el izquierdismo era el remedio a la enfermedad senil del comunismo (Cohn-Bendith, 1969).

En este contexto de protesta juvenil, España y Argentina experimentaron evoluciones políticas contrarias. En el primer caso, a pesar de la larga trayectoria de la dictadura implantada tras la Guerra Civil, la llegada a la arena política de una generación joven, en un momento de profundas transformaciones socio-económicas en el país, hizo posible que la ola de 
contestación transnacional alcanzara a España, donde adquirió un fuerte contenido antifranquista. El declive del franquismo se aceleró con una intensa movilización social, y con el fortalecimiento del partido comunista (PCE) y la aparición de otros de extrema izquierda, a pesar de la represión. A partir de 1975 se abrió el complejo proceso de transición a la democracia, durante el cual la izquierda revolucionaria entró en crisis (Molinero e Ysàs, 2016). En Argentina, la inestabilidad política había sido una constante desde 1955; la proscripción del peronismo y la represión de la disidencia fueron sus rasgos más visibles. Desde finales de los años sesenta comenzaron a proliferar las organizaciones de extrema izquierda, nutridas por esta nueva generación, que en buena parte apostó por el empleo de las armas (Calveiro, 2005). Tras el regreso de Perón desde el exilio en 1973 y su muerte un año más tarde, su esposa María Estela Martínez asumió el poder en un país con una creciente conflictividad política y social, hasta que en 1976 un nuevo golpe militar instauró un régimen dictatorial que se prolongaría durante siete años (Franco, 2012). La juventud, sospechosa de estar embebida del "veneno subversivo", fue sin duda su principal enemigo (Vannucchi, 2007, p. 22). En suma, cuando una dictadura declinaba, la otra recién comenzaba, hecho que explica los flujos migratorios y la disparidad en la evolución de las tensiones entre vida y militancia en el universo de la izquierda revolucionaria.

En la cultura rebelde juvenil de la época, la articulación entre lo individual y lo colectivo fue constante, con la afirmación de las subjetividades, la importancia concedida al sexo y el auge del movimiento feminista (Zanzarini-Fournel, 2000, p. 497). A uno y otro lado del Atlántico, la difusión del movimiento feminista de segunda ola tuvo diferentes alcances: en España surgieron asociaciones de mujeres que a partir de 1975 irrumpieron en el debate público y dejaron su impronta en los partidos de izquierda y en general en la agenda política, en torno al lema de "lo personal es político" y la demanda de derechos reproductivos (Nash y Torres, 2009). Con paradojas y límites, tras un intenso trabajo de reflexión y discusión, hubo una confluencia entre feminismo y militancia en la extrema izquierda, que hizo aflorar las contradicciones en las prácticas políticas y en la vida cotidiana (Moreno Seco, 2013). Por el contrario, en Argentina la segunda ola feminista, que también reclamaba una libertad de decisión sobre el propio cuerpo y planteaba nuevas concepciones acerca del amor y las relaciones familiares, se desarrolló al margen de los partidos de la nueva izquierda (Trebisacce, 2013). Las militantes de estas formaciones en su mayoría sintieron como ajenas las causas defendidas por el feminismo, que fue percibido como "cosa de extranjeras" o fue tildado de "desviación" pequeñoburguesa frente al objetivo prioritario de hacer la revolución (Rodríguez, 2016). Si bien no siempre cuestionaron las relaciones de subordinación presentes en los espacios de militancia, la práctica cotidiana generó numerosas tensiones y paradojas en las estructuras políticas en que estaban insertas (Andújar et al., 2005).

Para analizar cuestiones como la construcción de las subjetividades, el desarrollo de los afectos y los cambios en las relaciones familiares en un contexto de militancia política, esta investigación ha recurrido a una metodología cualitativa sustentada en fuentes orales y correspondencia privada. Como apunta Miren Llona (2012), la memoria y los testimonios se erigen en un medio excepcional para el estudio de las identidades y de los procesos de creación del sujeto. Por otro lado, aunque en ocasiones se ha señalado que mujeres y hombres recuerdan de manera diferente, ellas insertas en un discurso colectivo y ellos con un mayor hincapié en la experiencia individual, con tintes heroicos, esta autora subraya la necesidad de evitar aplicar de manera mecánica tales estereotipos. Nos hemos servido de entrevistas de producción propia, publicadas en libros de testimonios o depositadas en la Fundación 10 de Mayo de Madrid y en el centro Memoria Abierta-Archivo Oral de Buenos Aires. Por su parte, los epistolarios del fondo Cartas de la dictadura, albergados en la Biblioteca Nacional de Buenos Aires, nos permiten acceder a una escritura cotidiana, exenta del tamiz de la memoria, que otorga voz a quienes compusieron el exilio anónimo y el denominado de "segunda fila". Las cartas son el soporte idóneo para mostrar la comunión que se produjo - en buena parte de los casos de manera inconsciente- entre lo privado y lo público, lo personal y lo político. A pesar de la censura, las cartas privadas se convirtieron en el sostén de una comunidad emocional atravesada por la violencia y al mismo tiempo en la expresión manifiesta de un compromiso transgresor, que se negó a acatar el silencio que debía imponer el destierro.

\section{CONVERTIRSE EN MILITANTES: FAMILIA, CONVIC- CIONES Y EMOCIONES}

La izquierda revolucionaria que irrumpió en los años setenta presentó una composición novedosa respecto a los partidos tradicionales, ya que incorporó a un gran número de mujeres en un mundo tradicionalmente masculino. En España, las principales 
formaciones de la extrema izquierda fueron las maoístas Partido del Trabajo de España (PTE), Organización Revolucionaria de Trabajadores (ORT) y Movimiento Comunista (MC), y la trotskista Liga Comunista Revolucionaria (LCR), que presentaban en torno a un $30 \%$ de mujeres en su militancia, con una media de edad de 25 a 30 años (Equipo Seis, 1977; Wilhelmi, 2016). Estas militantes, primero con el objetivo de extender su influencia entre las mujeres y después por el impacto del feminismo, crearon estructuras organizativas propias en el seno de sus partidos o asociaciones feministas vinculadas a los mismos, y lograron que numerosas demandas feministas fueran incorporadas en sus formaciones, en especial en el MC y la LCR, y en menor medida en el PTE y la ORT. Aunque el acceso a puestos de poder interno no era equilibrado, alcanzaba proporciones mayores que en el resto de los partidos políticos (Moreno Seco, 2015).

En Argentina las dos organizaciones político-militares que tuvieron mayor desarrollo y atrajeron a un alto número de jóvenes fueron Montoneros, cuyas banderas más visibles eran la defensa de la justicia social y una patria socialista, y el Partido Revolucionario de los Trabajadores-Ejército Revolucionario del Pueblo (PRT-ERP), guevarista, de tendencia marxistaleninista. Ambas fundaron sus propias "secciones femeninas", que tuvieron una breve duración pues no fueron el resultado de una reflexión interna ni mucho menos producto de la influencia feminista (Grammático, 2005). Se estima que las mujeres representaron un $30 \%$ en Montoneros y un $40 \%$ en el PRT-ERP (Diana, 1996; Pozzi, 2001). Un número significativo que en ninguno de los dos casos se vio reflejado en las direcciones de las organizaciones políticas, ya que pese a las críticas a los partidos tradicionales de la izquierda fueron movimientos con una rígida estructura autoritaria y vertical (Carnovale, 2008), de corte patriarcal.

Como subraya della Porta (1998), la experiencia de la violencia y también los afectos y las redes personales fueron cruciales en la incorporación a grupos clandestinos de la nueva izquierda. Diversas autoras han señalado que las militantes ingresaron en las agrupaciones político-militares al entrar en la universidad o a través de un hombre - novio, amigo, hermano- (Pascuali, 2005). Sin embargo, sus testimonios dan cuenta de una casuística más variada. Como afirma Mercedes Yusta (2015), el acceso a la militancia a través de amistades y familiares es un patrón que se repite tanto en hombres como en mujeres, revelando una aproximación emocional al compromiso político. También se suele indicar que la militancia surgió dentro de hogares despolitizados o conservadores, que precipitaron el activismo en organizaciones de signo opuesto. No obstante, junto a la ruptura y el conflicto generacional, también fue frecuente la continuidad con las familias de origen (Oseka, Voglis y von der Goltz, 2013). Según los estudios de Ollier (1998), una parte del discurso revolucionario fue cultivado durante la niñez y la adolescencia, de forma que en numerosos casos ya se había producido un proceso de radicalización ideológica previo al ingreso en la extrema izquierda. La visión de la política como confrontación revolucionaria fundada en el paradigma amigo/enemigo encontró antecedentes en las disyuntivas entre franquismo/ antifranquismo o peronismo/antiperonismo. En definitiva, muchas y muchos jóvenes encontraron en sus propias casas el mejor caldo de cultivo para desarrollar un compromiso político. En el caso de las familias exiliadas en Argentina tras la Guerra Civil española y durante la posguerra, sus jóvenes se habían socializado en el recuerdo idealizado de la Segunda República y en la narración heroica de la contienda y la lucha antifascista (Ortuño Martínez, 2015). En España, la represión impuso silencios y miedo, pero también relatos entrecortados o expresados en voz baja de experiencias de la guerra y del maltrato en las cárceles franquistas, que provocaron sentimientos de orgullo o de indignación a los que se intentó dar salida con el ingreso en la militancia clandestina.

Al ser interrogada sobre su acercamiento a la política, Beatriz Ruiz, perteneciente a Unión de Estudiantes Secundarios - frente estudiantil de Montoneros-, indica:

Tal vez, pienso, fue por el hecho de que mis padres fueron laburantes [trabajadores] o que mi papá vivió la Guerra Civil siendo chico (Guelar, Jarach y Ruiz, 2003, p. 95).

Sin embargo, su ingreso definitivo en la militancia se produjo tras un hito histórico: el asesinato de Salvador Allende en 1973. Según Silvia Ramírez, integrante del MC, su familia se lo puso fácil a ella y a su hermana, porque sus padres militaban en el PCE y aunque ellas escogieron otro partido "porque somos de otra generación", sus progenitores entendían su opción por el compromiso político. Entre sus recuerdos de infancia, rememora a su madre destruyendo material de propaganda cuando se declaraba el estado de excepción, y las canciones de la Guerra Civil o la Internacional, que solo se podían entonar en casa (entrevista, 9 de octubre de 2011). 
Pero en una militancia en que no había solución de continuidad entre lo público y lo privado las relaciones con la familia de origen presentaron abiertas fracturas, provocadas por motivos ideológicos, por determinados orígenes sociales - en particular por el rechazo a la burguesía-, por formas de vida tradicionales o por la incomprensión ante el miedo y el silencio de sus mayores. Militante del MC, Manuel se distanció de sus padres, a los que consideraba muy buenas personas, porque "yo en esa época pensaba que eran gente burguesa, que lo que tenía que hacer era desclasarme... Unas neuras potentes" (Cucó i Giner, 2016, p. 142). Buena parte de las y los jóvenes de las clases medias argentinas provocaron serias desavenencias en las familias de origen por contravenir su identidad antiperonista (Spinelli, 2013). Marcia Schvartz, por ejemplo, cuyo padre militó durante su juventud en el Partido Comunista de Argentina y cuya madre lo hizo en la Unión Cívica Radical, afirma que ella siempre se "sintió" peronista, y por eso se unió a Montoneros ${ }^{1}$. Dichos conflictos adquirieron un peso significativo entre quienes se adscribían a las clases altas argentinas, como queda reflejado en la trayectoria y en el testimonio de la escritora Clara Obligado (entrevista, 29 de septiembre de 2019). Pero hay que tener en cuenta que, además de los choques identitarios por cuestiones políticas y de clase, el género, en este caso el hecho de ser mujeres, profundizó las marcas de las rupturas familiares por haberse apartado del camino previsto para ellas. Este aspecto estuvo presente en España y en muchas de las familias republicanas emigradas a Argentina, de quienes a priori se suponía un progresismo que se diluía en la intimidad (Paula Garganta de Urrutia, entrevista, 23 de septiembre de 2019).

Junto con el aprendizaje político y de valores en el seno familiar, la decisión de adoptar una militancia política alternativa también estuvo marcada en ocasiones por elementos más personales. Las jóvenes comprometidas de los setenta se identificaban con modelos de mujeres independientes, que se reafirmaban en oposición a la generación anterior de mujeres adultas $-y$ anticuadas -, por lo general sus propias madres, amas de casa cuyo proyecto de vida despreciaban (Cosse, 2010). En el caso de los varones, el rechazo hacia sus padres podía estar motivado porque representaban a profesionales acomodados que actuaban de forma autoritaria en sus familias. En opinión de Evans (2009, pp. 338-339), mientras los hombres criticaron el poder de sus padres, las mujeres cuestionaron además la jerarquía de género de sus familias. En definitiva, hubo una oposición generalizada a los principios, creencias y comportamientos asociados a la generación preceden- te, pero como hemos visto no siempre se produjo un "quiebre generacional" ni un distanciamiento absoluto de las familias de origen.

Por otro lado, no se encuentran diferencias entre mujeres y hombres en la importancia concedida a las convicciones ideológicas en la decisión de comenzar a formar parte de una organización política, estuvieran más o menos definidas, en una época de proliferación, escisiones y refundaciones de partidos de la nueva izquierda. Se creía que la utopía de una sociedad mejor, justa y libre podía llegar a convertirse en realidad si se pasaba a la acción, de ahí el auge de opciones políticas diferentes a los tradicionales partidos de izquierda (Tortti, 2014; Wilhelmi, 2016). Las fuentes ideológicas que sustentaron la militancia fueron diversas: el marxismo-leninismo, que interpretaba el compromiso como entrega total; el guevarismo, con su hincapié en la ética personal; el maoísmo, que concedía gran importancia a la coherencia entre ideología y prácticas de vida; el trotskismo, que insistía en el debate dentro del partido y estaba abierto a comportamientos alternativos; el tercermundismo, con la mitificación de procesos antiimperialistas; y el peronismo de izquierda, que mostraba "lealtad" a sus líderes - Perón y Eva- y aspiraba a un "socialismo nacional". Estos principios ideológicos sustentaron un universo simbólico que ofrecía explicaciones a todo, desde los intereses del capitalismo internacional a la elección de pareja.

El ingreso en un partido se fundaba también en la identificación con grandes principios dotados de un fuerte componente emocional como la justicia, la libertad o la solidaridad con los pueblos explotados. En ese sentido, puede hablarse de algunos "hitos emocionales revolucionarios". En primer lugar, se compartieron mitos como el de una idealizada clase obrera, en especial entre quienes provenían de estratos medios; o el de líderes como el Ché Guevara, un modelo de compromiso por su entrega e idealismo, que ofrecía un ideal de masculinidad revolucionaria. En segundo lugar, algunas fechas adquirieron un alto contenido emocional, como la Guerra Civil española, el mayo francés del 68, el fin del gobierno de Allende, la muerte de Franco o el golpe militar en Argentina. En tercer y último término, ciertos enclaves se convirtieron en una suerte de "paraísos revolucionarios". La seducción que ejercía la violencia en algunos sectores de esta juventud militante condujo a la admiración hacia China, Vietnam, Cuba o París, por la capacidad de resistencia y contestación de sus pueblos, que contrastaba con la grisura de la España franquista y de la Argentina de buena parte de los setenta. 
En suma, más allá de los riesgos que pudiera entrañar, se percibió la militancia como un medio para alcanzar la utopía, que combinaba la solidaridad y la entrega generosa con posturas mesiánicas, actitudes heroicas y una disciplina férrea (Cucó i Giner, 2008). Unos valores que definían un sujeto militante en masculino, un molde en que no siempre encajaron las mujeres y algunos hombres que no se ajustaban a los patrones de masculinidad hegemónica en estas culturas políticas (Clifford, 2012).

\section{NUEVAS FAMILIAS, AFECTOS Y MILITANCIA}

Dentro del ideario revolucionario, el compromiso político fue concebido como una forma de entender el mundo y de afrontar la vida desde una actitud contestataria (Oberti, 2013). Se trató de una militancia total que abarcaba la vida cotidiana y la intimidad, donde lo colectivo estaba por encima de lo individual y del grupo familiar. Para algunas mujeres la militancia llegó a ser considerada como "una especie de útero que te contenía en todos los terrenos: político, cultural, afectivo" (Testimonio de Graciela Daleo, en Diana, 1996, p. 270). La politización de lo privado marcó a esta juventud revolucionaria. En las condiciones especiales de la clandestinidad, afloraron numerosas tensiones entre la teoría y la práctica, el deseo y la realidad, que llevaron a los y las jóvenes militantes a asumir un régimen emocional donde reinó la constante pugna entre el ser y el deber ser. En los partidos maoístas, por ejemplo, donde la autocrítica era un ejercicio básico dentro de las células, se discutían de forma colectiva aspectos de la organización y de la vida cotidiana, para decidir sobre prioridades políticas, pero también criticar actitudes consideradas pequeñoburguesas e insistir en la conveniencia de abandonar los estudios por el trabajo manual o incluso de cambiar amistades o relaciones sentimentales. La integrante del MC Cristina Piris recuerda:

em tocà deixar el nóvio, perquè el nóvio s'havia deixat el partit $\mathrm{i}$ aleshores era una mala influència tenir-ne un que no fóra del partir. I vivía amb ell, i no! Vindre a casa i dir-me: agafa la maleteta, fes-te la maleta i te'n vens amb mi i deixes de viure amb eixe xic. I jo, plorant, plení la maleteta, i a anar-me'n, i deixar al xic! (Cucó i Giner, 2016, p. 166).

Las jóvenes, además, en consonancia con el precepto revolucionario de subvertir el orden social, político y cultural, tendieron a cruzar los límites marcados por los discursos normativos de género. Con acciones que a simple vista pudieran parecer superficiales, propusieron transformaciones profundas en las relaciones entre mujeres y hombres, así como entre distintas generaciones:
Queríamos cambiar todo, hacíamos todo lo que estaba mal visto, no podías usar pantalones, entrar sola a un bar, fumar en público. De hecho nosotras [...] hacíamos todo lo que estaba mal [...]. Después lo de la militancia clandestina, lo de hacer cosas absurdas, venía como incorporado a esto de hacer lo que estaba prohibido (Testimonio de María Cristina Pinal, en Oberti, 2015, p. 143).

Como ha señalado Oberti (2015), quienes formaban parte de una agrupación política desarrollaron rituales específicos y símbolos propios. Su identidad militante supuso un estilo informal de vestir y de comportarse, en muchos casos un estado civil y hasta un nombre diferente -menos clásico y con impronta revolucionaria-. En palabras de Kornetis (2015), la estética progre se convirtió en una codificación de la rebeldía política. Contribuyó a extender la identificación emocional con las opciones políticas y a consolidar su identidad militante.

La militancia en la extrema izquierda constituyó una entrega total de los cuerpos a la revolución. El compromiso político imantó la vida social, amorosa, sexual. Entablar una relación afectiva, comenzar a vivir en pareja y tener o no descendencia fueron decisiones con efectos políticos (Cosse, 2017). Para esta juventud militante, la pareja, y en ciertos contextos la familia que se formaba, también tenían que ser revolucionarias. No bastaba con militar a tiempo completo o proletarizarse, había que confiar el cuerpo y los afectos a la causa revolucionaria. La elección de la pareja tenía un componente político, pues se consideraba que debía existir una relación entre las sintonías políticas y las afectivas (Andújar, 2009). Como recuerda un militante del MC, se enamoró de una joven porque se sintió atraído por su origen obrero, su integridad moral y su activismo sindical (Cucó i Giner, 2016, pp. 142-143). El modelo de pareja cuyos dos miembros tenían un compromiso activo con la política fue promovido e idealizado:

Eso era entre nosotros el amor, la pareja. La entrega a la militancia hacía que la entrega del uno al otro fuera sublime, que la identificación fuera máxima. Esa especie de sacrificio permanente al que estábamos entregados, se intensificó en las épocas de mayor represión, en las que el hoy era lo único que existía. [...] Recuerdo los únicos quince días que vivimos juntos. Los sobresaltos a la noche [...]. La forma desesperada de hacer el amor como medio de pelear contra la muerte (Testimonio de Mariana, en Diana, 1996, p. 153).

Si bien estas uniones adquirían unas características especiales por la inminencia de posibles pérdidas en tiempos marcados por la violencia y la represión, y si 
bien el peligro podía darle a cada encuentro una especial intensidad erótica (Cosse, 2010), también es cierto que el espacio de la pareja quedó ocluido por la dinámica de la militancia y por la disciplina que cada organización se empeñó en aplicar a los cuerpos y a la sexualidad. Los testimonios revelan que el silencio impuesto por la clandestinidad y la intensidad del activismo dificultaban las relaciones de pareja, como recuerda Inmaculada Fernández, perteneciente al PTE (entrevista, 27 de junio de 2017). Además, la pareja militante solía mostrar la imagen de una relación discreta (Testimonio de Peti, en Diana, 1996, p. 71). Una seriedad que reflejaba la importancia concedida a lo colectivo frente al individuo, a supeditar las emociones a la razón revolucionaria, actitud que en ocasiones entraba en abierta contradicción con la realidad (del Río, 2012, p. 43-44). En el mismo sentido, los -y especialmente las- militantes se autoexigían acentuar rasgos atribuidos a la masculinidad, como la dureza, la rigidez o la valentía, incluso para ser aceptadas por los propios compañeros de su célula o de organización.

La moral revolucionaria repudió la revolución sexual en tanto expresión de la moral burguesa. Por este motivo, sobre todo en el caso español, y para integrarse en la sociedad y no llamar la atención en un contexto de clandestinidad, se impulsó el matrimonio de las parejas. Como señala un militante del MC: "Yo no tenía ganas de casarme, al contrario, yo no pensaba casarme en mi vida [...], pero como en ese momento tocaba, pues me caso" (Cucó i Giner, 2016, p. 143). Las infidelidades eran percibidas como un elemento negativo tanto en el plano personal como en el político, pero mientras en España nunca se llegó a sancionar a ningún militante por ello, en Argentina el régimen emocional impuesto en las organizaciones clandestinas supuso el castigo incluso de dirigentes (Cosse, 2017). Del mismo modo, se rechazó la homosexualidad, porque se consideraba que no era entendida por las masas populares o constituía una "desviación" pequeñoburguesa. Se dieron casos de militantes lesbianas o gais forzados a formar un matrimonio heterosexual (Arenes y Pikielny, 2016, pp. 223-224; Rodríguez Tejada, 2009, p. 399). Mención aparte merecería la experiencia de las organizaciones de liberación homosexual, que surgieron entonces en ambos países, y su relación con los partidos de la nueva izquierda revolucionaria (Insausti, 2019; Vespucci, 2017).

Sin embargo, en algunas organizaciones la situación fue evolucionando hacia una abierta aceptación de la libertad sexual, no sin contradicciones. Según Cristina Piris, la influencia del feminismo ayudó a atemperar la estricta moral revolucionaria, al conceder importancia a los afectos y al derecho al placer (Cucó i Giner, 2016, p. 166). A medida que avanzaron los años setenta, se extendieron las relaciones no sancionadas por el matrimonio; de acuerdo con el testimonio de Montserrat Cervera, de la LCR, ligar con unos y con otros era una moda ${ }^{2}$. Algunas militantes proyectaban una imagen de mujeres atractivas y liberadas, incluso entre los hombres de izquierda, juicio que no tenía lugar de manera recíproca (Silvia Ramírez, entrevista, 9 de octubre de 2011). Con el tiempo, dirigentes de la LCR y el MC aceptaron abiertamente la homosexualidad, aunque seguía siendo condenada por representantes de la ORT o el PTE (Ruiz y Romero, 1977, p. 45, p. 108 y p. 164).

La moral revolucionaria, además, estableció como principio la igualdad entre los sexos. Pero como remarcó Marta Vasallo (2009, p. 26), “de la teoría a la práctica la brecha era importante". El propio Luis Mattini, último Secretario General del PRT-ERP, reconoce que el machismo impregnaba su organización, incluso a él mismo (2007, p. 12). Según una exiliada argentina en España, fue muy evidente la contradicción entre los valores de la izquierda revolucionara y las actitudes de la vida privada:

de izquierda y de peronistas: iAh! ihermano!, iel pueblo!, iel pueblo! Y con tu compañera eres un hijoputa, y como padre eres un cerdo [...]. Bueno, y entonces, ¿dónde está la historia? (del Olmo, 2003, p. 295).

\section{Francisca Sauquillo considera que}

la ORT, pues era de machista igual que era toda la sociedad y no por ser de izquierdas, como decíamos nosotras entonces, se era menos machista, era... eran igual de machistas. Otra cosa es que estaba más... un poquitín más, más... peor visto ¿no? (entrevista, 20 de diciembre de 2012).

Algunos de tantos ejemplos que inciden en la porosidad que existió entre el mundo militante y el sexismo de la sociedad de la época (Cataruzza, 2008).

En el MC, una encuesta realizada por la estructura de mujeres dedicó una especial atención al reparto de tareas domésticas y de cuidado en las parejas militantes, que se entendía como un elemento inseparable de la opción política ${ }^{3}$. En reuniones de mujeres del partido debatían sobre las relaciones con sus compañeros:

Qué te pasa en el trabajo doméstico, y qué te pasa con el cuidado de los niños, y qué te pasa en las reuniones políticas cuando no tienes lugar para opinar o no te atreves a hablar, y luego qué te pasa con tu pro- 
pio cuerpo, incluso empezamos a hablar de sexualidad (Luz Quiñonero, entrevista, 23 de marzo de 2012).

Varios testimonios insisten en que las integrantes de la organización de mujeres del partido expresaban con rotundidad sus reivindicaciones y apelaban a la coherencia de sus camaradas, que con frecuencia se sentían interpelados por ellas. Según una militante:

Crec que als xics també els hem educat una miqueta en eixe camp. [...] Crec que els hem fet una miqueta més tendres, que els hem fet una miqueta més responsables -no molt- en el camp domèstic (Cucó i Giner, 2016, p. 203).

Por otro lado, en diferentes formaciones, ellas hacían compatible trabajo y actividad política, por lo que se convirtieron en proveedoras del sustento familiar, mientras ellos se dedicaban en exclusiva a la militancia, hecho que pudo contribuir a una reformulación de la masculinidad de estos jóvenes, educados en otros valores ${ }^{4}$. Una inversión de roles similar se dio en las parejas argentinas en el exilio. El abandono de la militancia total y la mayor dificultad, en líneas generales, para conseguir un trabajo remunerado llevó a los hombres a recluirse en el espacio privado, lugar para el que no estaban preparados ni cultural ni emocionalmente. Las mujeres por su parte, como se ha comprobado para otros destinos y períodos históricos (Franco, 2009; Moreno Seco y Ortuño Martínez, 2013), se convirtieron en el soporte material y espiritual del exilio, por su capacidad de adaptarse a las nuevas circunstancias. Esta situación aceleró la ruptura de muchas parejas. Además, las crisis sentimentales estuvieron provocadas en ocasiones por crisis ideológicas a ambos lados del Atlántico. En España, se vieron acentuadas tras el final de la dictadura. En Argentina, a las muertes y desapariciones, que dieron lugar a inevitables fracturas, se sumó el declive de las convicciones que sustentaban a estas parejas, como sucedió también en el exilio (Vasquez y Araujo, 1990; Paula Garganta de Urrutia, entrevista, 29 de septiembre de 2019) ${ }^{5}$.

No obstante, entre todas las contradicciones que acarreó la militancia, uno de los puntos más conflictivos fue la maternidad y la paternidad. En ocasiones el discurso oficial de los partidos incitaba a las militantes a ser madres para la patria o la futura sociedad revolucionaria. En esta línea se insertaron las consignas de las dos principales organizaciones armadas argentinas. El documento Moral y Proletarización dictaba unas normas específicas para que las y los militantes del PRT-ERP afrontasen de manera revolucionaria "la natural e instintiva tendencia del ser humano a prolongar la existencia de su especie". Tenían que desprenderse de actitudes individualistas hacia sus hijas e hijos, quienes debían compartir con sus progenitores la vida de militancia. Dentro de esta agrupación se mitificó el modelo de la madre vietnamita, que amamantaba a su hijo con el fusil al lado (Martínez, 2015). Sin embargo, el embarazo y la lactancia establecían limitaciones en las actividades políticas de las mujeres y contradecían el objetivo de la crianza colectiva. Por el lado de Montoneros no hubo un programa específico sobre la maternidad y la paternidad, pero también existía ese ideal de una crianza socializada, que consideraba a la descendencia de cada militante como hijos e hijas del conjunto de la agrupación. No obstante, ambas formaciones se distinguían por el maternalismo propio del peronismo histórico, que aludía a las labores de cuidados de las mujeres (Grammático, 2012).

Por el contrario, en los partidos de extrema izquierda españoles, la maternidad y la paternidad fue un aspecto ausente del proyecto político, que no concedía importancia ideológica a la familia, entendida de manera creciente como un residuo de la sociedad burguesa que había que superar, y en consonancia además con la distinción que el feminismo del momento hacía entre sexualidad y maternidad (Moreno Seco, 2017). Aunque en reuniones de células del PTE se llegó a proponer que algunas parejas militantes tuviesen descendencia, en términos generales el recurso a métodos anticonceptivos estaba extendido entre la juventud de la extrema izquierda (Inmaculada Fernández Arrillaga, entrevista, 27 de junio de 2017). En España, por tanto, no fue frecuente que las militantes quedaran embarazadas ${ }^{6}$. Según Montserrat Cervera, "si escogías la militancia, escogías no tener hijos"7. De hecho, según alguna dirigente, ciertas mujeres lucharon por su derecho a ser madres en organizaciones donde se creía que "la causa estaba por encima de todo" (Luz Quiñonero, entrevista, 23 de marzo de 2012).

Una vez más, al analizar los testimonios de las mujeres que pertenecieron a estas agrupaciones afloran las contradicciones surgidas entre la teoría y la práctica, entre el ser y el deber ser. Con o sin proyecto de crianza colectiva, en su inmensa mayoría fueron ellas quienes asumieron la tarea en solitario. Son numerosas las mujeres que afirman haberse sentido sobrepasadas por sus extenuantes jornadas de militantes, estudiantes, trabajadoras y madres, algunas de ellas siendo muy jóvenes (Diana, 1996). Aunque no fue habitual, también hubo varones que participaron en 
la crianza (Martínez, 2015; Sepúlveda, 2014). Al menos entre los argentinos, se tomó como un precepto revolucionario asumir la paternidad de aquellos niños y niñas cuyos padres habían muerto o estaban presos. Las cartas escritas durante el exilio trasmiten el afecto y la ternura que algunos hombres sintieron por los hijos e hijas de sus parejas, fruto de relaciones anteriores ${ }^{8}$. Si bien a través de ellas intuimos que los cuidados recayeron sobre las madres, dan cuenta de un régimen emocional referente a la paternidad que difería del de sus predecesores y entraba en contradicción con la máxima revolucionaria de supeditar las emociones a la razón.

También proliferaron aquellas militantes para quienes la experiencia de la maternidad fue un estímulo para continuar en la lucha por una sociedad más justa y libre de la doble moral burguesa. Así, Marta Libenson, a punto de volver a Argentina para seguir combatiendo contra la dictadura, reforzaba su postura política, a pesar del miedo y de las contradicciones, por medio de la figura de su hija. En estos términos se lo transmitía a su pareja:

Cómo sabés mi limitación principal entre una serie de cosas es Ana Victoria pero lo que me he dado cuenta es que justamente por ella, por cómo se gestó y para qué futuro la criamos, no puede ser una limitación para ninguno de nosotros. Al contrario. Tiene que ser una guía ante cualquier decisión ${ }^{9}$.

En tercer lugar, además de como un lastre o un acicate, hubo quien vivió su maternidad con naturalidad. Cuando contaron con sólidas redes familiares o de amistad pudieron compaginar crianza y compromiso. Cristina Piris compartió un piso con unas amigas, una de las cuales tenía una niña que atendieron entre todas (Cucó i Giner, 2016, p. 203). En definitiva, hubo tantos modelos de madres como de mujeres que experimentaron la maternidad, algunos de ellos contra-hegemónicos (Ricard, 2017). Fueron muchas las que transgredieron, también a través de sus maternidades, los tradicionales papeles femeninos que les habían sido asignados, en ocasiones abandonando incluso sus hogares y dedicándose en exclusiva a la militancia. Así lo hizo Liliana Belloni, quien dejó a su hijo con el padre y se fue a vivir con unos compañeros de agrupación. Antes, su madre, Lili Massaferro, ya se había unido con plena dedicación a la causa de Montoneros tras el asesinato de su hijo ${ }^{10}$. Se dieron otros casos de militancia de madres e hijas, como Carmina Pacheco, quien ingresó en el MC después de sus hijas Silvia y Sonia Ramírez, por convicción política y por un deseo de protegerlas (entrevista, 6 de junio de 2012). De manera que en ocasiones se produ- jo el transvase de causas y de un lenguaje político de la generación más joven a sus mayores, como sucedió, por ejemplo, en Madres de Plaza de Mayo, donde además se hizo de la maternidad una construcción política y colectiva de mujeres para luchar contra la violación de los derechos humanos (D’Antonio, 2007).

Por otro lado, de alguna manera la célula o el partido se convirtieron en una nueva familia. El desarraigo que pudo provocar la ruptura con la familia de origen o con las amistades de la infancia fue compensado con la creación de nuevas redes entre militantes. De hecho, fue frecuente que varias parejas vivieran en el mismo piso, compartiendo gastos y creando espacios donde se discutía de política, se acogía a compañeros y compañeras que perseguía la policía, y se forjaban amistades reforzadas por la coincidencia en los planteamientos políticos.

\section{REFLEXIONES FINALES}

Desde finales de los años setenta, la experiencia de la militancia total cambió. El ciclo contestatario de los "largos sesenta" empezó a declinar, hecho que marcó a la izquierda revolucionaria. En España, la transición y el fin de la clandestinidad se saldó con la desaparición de algunos partidos y la evolución de otros hacia nuevos intereses. En el país austral, los ochenta supusieron el regreso de la democracia, con políticas de condena de la violencia tanto de los militares como de los grupos armados de izquierda, hecho que se unió al dolor de las ausencias, al silencio y al ostracismo. Pero en este diálogo constante entre lo público y lo privado, no puede olvidarse que también fue importante la entrada en la edad adulta de esa juventud rebelde, que ya empezaba a plantearse un futuro personal familiar, profesional- a medio plazo. Las reacciones a este nuevo escenario fueron diversas: hubo quien se dejó llevar por el desencanto político (Beorlegui Zarranz, 2017), pero en otras ocasiones se optó por nuevas o anteriores militancias, sobre todo en el sindicalismo, el ecologismo, el pacifismo y en especial el feminismo. Después de años de vida sentimental vertiginosa, llegaría la estabilidad de pareja, desde una relación igualitaria y abierta, cuando no la ruptura, o la dedicación a la maternidad o la paternidad. Fue además una nueva etapa de retomar afectos, por ejemplo con la familia de origen.

En definitiva, a lo largo de este trabajo hemos corroborado cómo las complejas relaciones entre activismo político y vida cotidiana arrojan nuevos significados desde un enfoque de género, que hace patentes las contradicciones entre el compromiso y la transgresión. 
La politización de lo privado supuso que la contestación política en la izquierda revolucionaria condujera a un crecimiento personal, a experimentar nuevas maneras de comportarse y a explorar unas relaciones igualitarias, pero también al sectarismo, al puritanismo y a importantes costes emocionales y fracturas familiares. Entre quienes dedicaron su vida al compromiso total, la transgresión, tanto política como personal, presenta diferentes consecuencias en función del género: ellas rompieron con el ideal de feminidad en que habían sido educadas y, en mayor o menor grado, con el ideal militante definido en masculino; ellos no tuvieron que hacerlo, pero en cierta manera se vieron obligados a replantear su forma de actuar tanto en el partido como en sus relaciones personales.

A partir del estudio en torno a la sexualidad, las parejas o las familias, la comparación de las experiencias española, argentina y del exilio muestra que las relaciones entre género, compromiso y transgresión en la militancia revolucionaria de los años setenta presenta líneas comunes, pero también matices que enriquecen nuestro conocimiento sobre la cultura juvenil transnacional de la época y la forma de entender y practicar la militancia integral, asumida como compromiso vital. Un compromiso que a ambos lados del
Atlántico, a pesar de la cronología disímil de sus dictaduras, estuvo signado por los aires revolucionarios de "los mayos del 68", por la segunda ola feminista, por las culturas políticas familiares y por la clandestinidad, la cual impuso un régimen emocional extremadamente intenso que se fundamentó en el peligro de represión y muerte, así como en la juventud. De ahí que la intersección entre género y edad nos haya permitido analizar con mayor riqueza la experiencia de la militancia en la izquierda radical de los años setenta, pues arroja luz sobre las tensiones, continuidades y fracturas entre distintas generaciones, que en ocasiones fueron vividas de manera diferente por hombres y por mujeres. Queda abierto a futuros trabajos el análisis de las percepciones de las hijas e hijos sobre sus mayores.

\section{AGRADECIMIENTOS}

Este trabajo se ha realizado en el marco del proyecto de investigación Género, compromiso y transgresión en España, 1890-2016 (FEM2016-76675-P), financiado por el Ministerio de Economía y Competitividad. Agradecemos la amabilidad de aquellas personas que han sido entrevistadas y cuyo testimonio se ha utilizado en este artículo.

\section{NOTAS}

1. Memoria Abierta-Archivo Oral. Buenos Aires, 2017. Ref. A00781

2. Fundación 1을 de Mayo, Archivo de Historia Oral, Madrid, Ref. FC2.

3. Archivo de la Democracia. Universidad de Alicante. Subfondo de Llum Quiñonero.

4. Seminario de Fuentes Orales, Madrid. Entrevista a Ángela Gutiérrez Suárez.

5. Por otro lado, el exilio aceleró algunos tiempos vitales y se convirtió en el espacio de primera convivencia para mu-

\section{BIBLIOGRAFÍA}

Andújar, A. (2009). El amor en tiempos de revolución: los vínculos de pareja de la militancia de los 70. Batallas, telenovelas y rock and roll. En: Andújar, A., D’Antonio, D., Gil Lozano, F., Grammático, K. y Rosa, M. L. (comps.). De minifaldas, militancias y revoluciones. Exploraciones sobre los 70 en la Argentina. Buenos Aires: Luxemburg, pp. 149-170.

Andújar, A., D’Antonio, D., Domínguez, N., Grammático, K., Gil Lozano, F., Pita, V. chas parejas de adolescentes, de entre 15 y 20 años, cuyos miembros antes de la partida todavía vivían con sus padres (Guelar et al., 2003, p. 125 y p. 236).

6. E incluso se dieron casos de abortos clandestinos o practicados en Londres (García de León, 2008, p. 120).

7. Fundación 1.o de Mayo, Archivo de Historia Oral, Madrid, Ref. FC2.

8. Cartas de Ricardo Zuker a Marta Libenson, cartas de Luis Mattini a Diana Cruces. Biblioteca Nacional Mariano

[...] y Vassallo, A. (comps.). (2005). Historia, género y política en los '70. Buenos Aires: Feminaria.

Arenes, C. y Pikielny, A. (2016). Hijos de los 70. Historias de la generación que heredó la tragedia argentina. Buenos Aires: Sudamericana.

Beorlegui Zarranz, D. (2017). Transición y melancolía. La experiencia del desencanto en el País Vasco (1976-1986). Madrid: Postmetrópolis.
Moreno (Argentina). Departamento de Archivos. Colección Cartas de la dictadura. Secciones Cristina Zuker y Diana Cruces. Serie correspondencia.

9. Cartas de Marta Libenson a Ricardo Zuker. Biblioteca Nacional Mariano Moreno (Argentina). Departamento de Archivos. Colección Cartas de la dictadura. Sección Cristina Zuker. Serie correspondencia.

10. Memoria Abierta-Archivo Oral, Buenos Aires, 2017. Ref. A00317A.

Calveiro, P. (2005). Política y/o violencia. Buenos Aires: Norma.

Carassai, S. (2013). Los años setenta de la gente común. La naturalización de la violencia. Buenos Aires: Siglo XXI.

Carnovale, V. (2008). Moral y disciplinamiento en el PRT-ERP. Nuevo Mundo. Mundos Nuevos [en línea]. Disponible en: http://nuevomundo.revues. org/38782 
Cattaruzza, A. (2008). El mundo por hacer Lucha Armada en la Argentina, 10, pp. 12-24.

Clifford, R. (2012). Emotions and gender in oral history: narrating Italy's 1968. Modern Italy, 17 (2), pp. 209-221.

Clifford, R., Gildea, R. y Warring, A. (2013) Gender and sexuality. En: Gildea, R., Mark, J. y Warring, A. (eds.). Europe's 68. Voices of Revolt. Oxford: Oxford University Press, pp. 239-257.

Cohn-Bendith, D. (1969). El izquierdismo, remedio a la enfermedad senil del comunismo. Buenos Aires: Grijalbo.

Coraza de los Santos, E. y Gatica, M. (2018). Los exilios políticos y la dimensión comparada: contribuciones a un campo en construcción. Nóesis. Revista de Ciencias Sociales y Humanidades, 27 (53) pp. 1-21.

Cosse, I. (2010). Pareja, sexualidad y familia en los años sesenta. Una revolución discreta en Buenos Aires. Buenos Aires: Siglo XXI.

Cosse, I. (2017). "Infidelidades»: Moral revolución y sexualidad en las organizaciones de la izquierda armada en la Argentina de los años 70. Prácticas de oficio, 1 (19), pp. 1-21. [En línea]. Disponible en: https://www.ides.org.ar/sites/ default/files/attach/1.-COSSE1.pdf

Cucó i Giner, J. (2008). Recuperando una memoria en la penumbra: el Movimiento Comunista y las transformaciones de la extrema izquierda española. Historia y Política, 20, pp. 73-96.

Cucó i Giner, J. (2016). De la utopia revolucionària a l'activisme social. El Moviment Comunista, Revolta y Cristina Piris. Valencia: Publicacions Universitat de València.

D’Antonio, D. (2007). Las Madres de Plaza de Mayo y la maternidad como potencialidad para el ejercicio de la democracia política. En Bravo, M. C., Gil, F. y Pita, V. (comps.). Historia de luchas, resistencias y representaciones. Mujeres en la Argentina, siglos XIX y XX. San Miguel de Tucumán: Edunt, pp. 283-303.

Diana, M. (1996). Mujeres guerrilleras. La militancia de los setenta en el testimonio de sus protagonistas. Buenos Aires: Planeta.

Eley, G. (2003). Historia de la izquierda en Europa, 1850-2000. Barcelona: Crítica.

Equipo Seis (1977). Un hombre, un voto. Guía electoral 1977. Madrid: Cambio 16
Evans, S. M. (2009). Sons, Daughters and Patriarchy. Gender and the 1968 Generation. American Historical Review, 114, pp. 331-347.

Franco, M. (2009). El exilio como espacio de transformaciones de género. En Andújar, A., D’Antonio, D., Gil Lozano, F., Grammático, K. y Rosa, M. L. (Comps.). De minifaldas, militancias y revoluciones. Exploraciones sobre los 70 en la Argentina. Buenos Aires: Luxemburg, pp. 127-145.

Franco, M. (2012). Un enemigo para la nación. Orden interno, violencia y "subversión", 1973-1976. Buenos Aires: FCE.

Frank, R. (2000). Introduction. En: DreyfusArmand, G., Frank, R., Lévy, M. F. y Zancarini-Fournel, M. (dirs.). Les années 68. Le temps de la contestation. Paris: Complexe, pp. 13-21.

García de León, M. A. (2008). Rebeldes ilustradas (La otra transición). Barcelona: Anthropos.

Grammático, K. (2005). Las mujeres "políticas" y las feministas en los tempranos setenta: ¿Un diálogo (im)posible? En: Andújar, A., D’Antonio, D., Domínguez, N., Grammático, K., Gil Lozano, F., Pita, V. [...] y Vassallo, A. (comps.). Historia, género y política en los '70. Buenos Aires: Feminaria, pp. 19-38.

Grammático, K. (2012). Mujeres montoneras: una historia de la Agrupación Evita, 1973-1974. Buenos Aires: Luxemburg.

Guelar, D., Jarach, V. y Ruiz, B. (2003). Los chicos del exilio. Buenos Aires: El País del Nomeolvides.

Hobsbawm, E. (1998). Historia del Siglo XX. Buenos Aires: Crítica-Grijalbo.

Horn, G. R. (2007). The Spirit of '68. RebeIlion in Western Europe and North America, 1956-1976. Oxford: Oxford University Press.

Insausti, S. J. (2019). Una historia del Frente de Liberación Homosexual y la izquierda en Argentina. Revista Estudos Feministas, 27 (2). [En línea]. Disponible en: https:// www.scielo.br/scielo.php?pid=S0104026X2019000200213\&script=sci_arttext

Klimke, M. y Scharloth, J. (2008). 1968 in Europe. A History of Protest and Activism, 1956-1977. Nueva York: Palgrave MacMillan.

Kornetis, K. (2015). 'Let's get laid because it's the end of the world': sexuality, gender and the Spanish Left in late
Fracoism and the Transición. European Review of History, 22 (1), pp. 176-198.

Lastra, S. (comp.) (2018). Exilios: un campo de estudios en expansión. Buenos Aires: CLACSO.

Llona, M. (2012). Historia oral: la exploración de las identidades a través de la historia de vida. En: Llona, M. (ed.). Entreverse. Teoría y metodología práctica de las fuentes orales. Bilbao: Universidad del País Vasco, pp. 15-59.

Mamzer, H. (2006). La identidad y sus transgresiones. La Ventana, 24, pp. 118-149.

Martínez, P. (2015). Género, política y revolución en los años setenta. Mujeres del PRT-ERP. Ituizangó: Maipue.

Mattini, L. (2007). Los Perros 2. Memorias de la rebeldía femenina en los 70'. Buenos Aires: Peña Lillo y Ediciones Continente.

Molinero, C. e Ysàs, P. (eds.) (2016). Las izquierdas en tiempos de transición. Valencia: Publicacions de la Universitat de València.

Moreno Seco, M. (2013). Compromiso político y feminismo en el universo comunista de la Transición. Cuestiones de Género, 8, pp. 43-60.

Moreno Seco, M. (2015). Engagement et genre dans l'extrême gauche espagnole des années 1970. En: Bergès, K., Burgos-Vigna, D., Ludec, N. y Yusta Rodrigo, M. (coords.). Résistantes, militantes, citoyennes. L'engagement politique des femmes aux XXe at XXIe siècles. Rennes: Presses Universitaires de Rennes, pp. 181-197.

Moreno Seco, M. (2017). Sexo, Marx y nova cançó. Género, política y vida privada en la juventud comunista de los años setenta. Historia Contemporánea, 54, pp. 47-84

Moreno Seco, M. y Ortuño Martínez, B. (2013). Exiliadas españolas en Francia y Argentina: identidades transnacionales y transferencias culturales. Storia delle donne, 9, pp. 161-196.

Nash, M. y Torres, G. (eds.). (2009). Feminismos en la Transición. Barcelona: Universidad de Barcelona y Sociedad Estatal de Conmemoraciones Culturales.

Oberti, A. (2013). Las mujeres en la política revolucionaria. El caso del PRT-ERP en la Argentina de los años 70. INTERthesis, Revista Internacional Interdisciplinar, 10 (1), pp. 6-36. 
Oberti, A. (2015). Las revolucionarias. Militancia, vida cotidiana y afectividad en los setenta. Buenos Aires: Edhasa.

Ollier, M. (1998). La creencia y la pasión. Privado, público y político en la izquierda revolucionaria. Buenos Aires: Ariel.

Olmo, M. del (2003). La utopía en el exilio Madrid: Consejo Superior de Investigaciones Científicas.

Ortuño Martínez, B. (2015). Jóvenes «expatriadas». Un acercamiento a la segunda generación del exilio republicano en $\mathrm{Ar}$ gentina durante los años 60 y 70 . Ayer 100 , pp. $123-147$

Oseka, P., Voglis, P. y von der Goltz, A. (2013). Families. En: Gildea, R., Mark, J. y Warring, A. (eds.). Europe's 68. Voices of Revolt. Oxford: Oxford University Press, pp. 46-71.

Pascuali, L. (2005). Narrar desde el género: una historia oral de mujeres militantes. En Andújar, A., D’Antonio, D., Domínguez, N., Grammático, K., Gil Lozano, F., Pita, V. [...] y Vassallo, A. (comps.). Historia, género y política en los '70. Buenos Aires: Feminaria, pp. 122-139.

Porta, D. della (1998). Las motivaciones individuales en las organizaciones clandestinas. En Tejerina Montaña, B. e Ibarra Güell, P. (eds.). Los movimientos sociales: transformaciones políticas y cambios culturales. Barcelona: Trotta, pp. 219-242

Pozzi, P. (2001). "Por las sendas argentinas...". EI PRT-ERP. La Guerrilla marxista. Buenos Aires: EUDEBA.

Ricard, P. (2017). Modelos de madres contra-hegemónicos. Análisis de la representación de la maternidad en la escritura a partir de Aparecida, de Marta Dillon. Descentrada, 1 (2) e024.
[En línea]. Disponible en: http://www. descentrada.fahce.unlp.edu.ar/article/ view/DESe024

Río, E. del (2012). De la indignación de ayer a la de hoy. Transformaciones ideológicas en la izquierda alternativa en el último medio siglo en Europa occidental. Madrid: Talasa.

Rodríguez, E. (2016). Mujeres en la periferia. Feminismos e izquierdas en la revista «Crisis». Argentina 1973-1976. En: Ramos, M. D., León Vegas, M., Ortega Muñoz, V. J. y Blanco Fajardo, S. (coords). Mujeres iberoamericanas $y$ derechos humanos. Experiencias feministas, acción política y exilios. Sevilla: Athenaica, pp. 155-177.

Rodríguez Tejada, S. (2009). Zonas de libertad. Dictadura franquista y movimiento estudiantil en la Universidad de Valencia, vol. II. Valencia: Publicacions de la Universitat de València.

Ruiz, F. y Romero, J. (eds.) (1977). Los partidos marxistas. Sus dirigentes, sus programas. Barcelona: Anagrama.

Sepúlveda, P. G. (2014). La maternidad y los hijos: un foco de tensión para la militancia femenina. Análisis de un grupo de militantes de organizaciones políticoarmadas de los años 70' en Argentina. Contenciosa, II (3). [En línea]. Disponible en: http://www.contenciosa.org/ Sitio/VerArticulo.aspx?i=36

Spinelli, M. E. (2013). De antiperonistas a peronistas revolucionarios. Las clases medias en el centro de la crisis política argentina (1955-1973). Buenos Aires: Sudamericana.

Tortti, C. (dir.) (2014). La "nueva izquierda" argentina (1955-1976). Socialismo, peronismo y revolución. Rosario: Prohistoria.
Trebisacce, C. (2013). Encuentros y desencuentros entre la militancia de izquierda y el feminismo en la Argentina. Estudos feministas, 21 (2), pp. 439-462.

Vannucchi, E. (2007). Recordar y entender. Carta abierta a los padres argentinos: la última dictadura militar, 1976-1983. Buenos Aires: Ministerio de Educación, Gobierno de la Ciudad.

Vasallo, M. (2009). Militancia y transgresión. En: Andújar, A., D’Antonio, D., Gil Lozano, F., Grammático, K. y Rosa, M. L. (comps.). De minifaldas, militancias $y$ revoluciones. Exploraciones sobre los 70 en la Argentina. Buenos Aires: Luxemburg, pp. 19-32.

Vasquez, A. y Araujo, A. (1990). La maldición de Ulises. Repercusiones psicológicas del exilio. Santiago de Chile: Sudamericana.

Vespucci, G. (2017). Homosexualidad, familia y reivindicaciones. De la liberación sexual al matrimonio igualitario. Buenos Aires: Universidad Nacional de San Martín.

Wilhelmi, G. (2016). Romper el consenso. La izquierda radical en la Transición española (1975-1982). Madrid: Siglo XXI.

Yusta, M. (2015). Con armas frente a Franco. Mujeres guerrilleras en la España de posguerra. En: Yusta, M. y Peiró, I. (eds.). Heterodoxas, guerrilleras y ciudadanas. Resistencias femeninas en la España moderna y contemporánea. Zaragoza: Institución Fernando el Católico, pp. 175-195.

Zancarini-Fournel, M. (2000). Conclusion. En: Dreyfus-Armand, G., Frank, R., Lévy, M. F. y Zancarini-Fournel, M. (dirs.). Les années 68. Le temps de la contestation. Paris: Complexe, pp. 495-502. 